Brown, R., Redmond, T., Sheehey, J., \& Lang, D. (in press, accepted 28/6/12). Mathematical modelling - an example from an inter-school modelling challenge. In NG Kit Ee \& Ngan Hoe (Eds.) Mathematical modelling - from theory to practice, National Institute of Education, Singapore.

\title{
Mathematical Modelling- an Example from an Inter-school Modelling Challenge
}

\author{
Raymond Brown \\ Griffith University \\ $<$ ray.brown@griffith.edu.au> \\ Joanne Sheehy \\ AB Paterson College \\ $<$ jsy@abpat.qld.edu.au>
}

\author{
Trevor Redmond \\ AB Paterson College \\ trd@abpat.qld.edu.au \\ Dawn Lang \\ A.B. Paterson College \\ $<$ dlang@abpat.qld.edu.au>
}

\begin{abstract}
The notion of mathematical modelling is not new; however, with the development and access to cheap, powerful calculator and computer technologies, students in schools are able to engage with sophisticated mathematical contexts that have relevance outside of the classroom, a view of mathematics not commonly held by students. From one of the workshops of modelling challenge, we analyse a conversation between a group of students as a way of providing a meaningful example of the types of conversations students have while they engage in thinking about and doing mathematical modelling.
\end{abstract}

A view often held by Mathematics teachers is one of students either having or not having the content knowledge of mathematics and then being either able or unable to use it proficiently. Teachers who embrace this view feel that content is fixed and often defined by what is developed in a text book (Smith, p. 390). As a result, the teaching pedagogy adopted by some teachers has been one of 'telling' the students the concepts they should learn. To assist in learning content, the teacher 'tells' the student by showing a worked example, providing little tricks to make attaining the answer easier, and by having the student practise the particular procedure a number of times. If students do not understand the content, "the teacher retells the procedure and the students continue to practise it" (Smith, p. 39).

Occasionally, time permitting; students are exposed to a context which may be construed to be authentic. In these situations, students are given the opportunity to use mathematical concepts and procedures that have been developed to explore that context. In many instances however, the 'authentic contexts' are contrived and the results obtained by students have 'nice' answers. That is, the problem was posed in such a way that there is one right way of arriving at the solution and the solution is unique. 
Subsequently, students develop a rigid view of mathematics. That is, they develop a view of Mathematics as having no real use apart from solving problems in a text book in a classroom setting; that there is a unique way of building a solution to every problem, and that solutions are always 'nice' and found in the back of a text book (Smith, p. 390). As a result, many students become disengaged with learning mathematics; they do not see mathematics as having any value or use outside the mathematics classroom and they endure their mathematics classes. In turn, this disengagement has an effect on teacher efficacy.

Ashton defines teachers "sense of efficacy" as a "belief in their ability to have a positive effect on student learning" (Ashton, 1985, p. 142; Smith 1996, p. 388) and that teachers build this sense of efficacy using "perceived past successes" (Smith, p. 389). Given this, the types of experiences the teacher has had in trying different pedagogies will impact not only on their willingness to try something new, but also on their perseverance in the face of adversity. This adversity may come from a number of sources, for example, adversity from students and parents in the way the concepts are being developed, adversity from administration in the form of a lack of provision of resources to adequately ensure the success of the initiative or a lack of professional development or adversity from colleagues that can be manifested in a variety of forms. According to Smith "a sense of efficacy is more appropriately understood as a fluid, dynamic set of beliefs than a fixed personality trait." (p.389) This understanding implies that given the right set of circumstances; appropriate support, adequate professional development and resources, teachers are able to modify and change their sense of efficacy and, in turn, their view of mathematics.

Society values knowledge, and largely sees it as a fluid rather than fixed quantity; however this is not generally attributed to Mathematics. Smith (1996) argues that mathematics no longer needs to be seen as a fixed collection of facts and procedures; rather it needs to be seen as a dynamic body of knowledge that is continually enriched through the making of conjectures and through the exploration of analysis and proof. "The fundamental goals of school mathematics are to teach students to understand and reason with mathematical concepts, solve problems arising from new and diverse contexts and develop sense of their mathematical power" (p. 393). Changing the face of mathematics in schools is the 2008 Queensland Mathematics B Syllabus where a number of key competencies are identified and developed on completion of the course. These competencies include "Collecting, analysing and organising 
information, communicating ideas and information, planning and organising activities, working with others and in teams, using mathematical ideas and techniques, solving problems and using technology" (p. 2).

Other sources of expertise such as Walser (2008) identify skill sets necessary for successful citizenship in the $21^{\text {st }}$ Century. These skill sets include abilities related to Critical Thinking, Problem Solving, Collaboration, Written and Oral Communication, Creativity, Self-Direction, Leadership, Adaptability, Responsibility and Global Awareness. The question then becomes, What may be done to provide teachers with the support necessary to consolidate or refine their sense of efficacy so as to enable them to develop and present courses of study enriched though conjecture and exploration, that will engage students in learning mathematics, and that will promote the development of skill sets that ensure student participation in the $21^{\text {st }}$ Century (Walser, 2008)? One form of such support may come through engagement in mathematical modelling.

Swertz and Hartzler (1991) suggest that mathematical modelling is "a mathematical process that involves observing a phenomenon, conjecturing relationships, applying mathematical analyses (equations, symbolic structures, etc.), obtaining mathematical results, and reinterpreting the model." For students to be able to build a mathematical model for a particular context, they need to make sense of the context being investigated, identify appropriate assumptions, select the appropriate mathematical concepts and procedures that might be useful in developing a mathematical model and develop a strategy that will allow them to combine those concepts and procedures in meaningful ways to build a model that represents the context. By doing this, students are required to draw on skill sets such as those described by Walser (2008). That is, they are required to be thoughtful as they draw conclusions and develop conjectures by looking for consistencies in the mathematics and consensus between the mathematical model and the context they are attempting to model. If they do not find either the consistency in the mathematics nor consensus between the mathematics and the context, then the students are forced, to revisit the context, to refine or change their assumptions, to reconsider the mathematical concepts and strategy they employed and attempt to resolve this conflict.

By engaging in this way, students are given opportunities to realise that the mathematics they develop in the classroom has relevance outside of the classroom. They are also given multiple opportunities to develop and to refine their 
understanding of the mathematical concepts used to develop the mathematical model. They are also encouraged to question their assumptions. Galbraith and Stillman (2001) have identified that assumptions are developed and refined at different times in the process of building a mathematical model, initially when the student first engages with the context, then during the building phase of the model and finally when the student looks for consensus between the model and the context. Teachers in identifying suitable modelling tasks for students to engage with provide rich social and cultural learning environments for their students centred on teaching and learning.

In Sociocultural approachs to teaching and learning, students and expert others work together on tasks to develop solutions to problems that have been posed. It is not the case of the teacher leading the discussion by 'telling' the students the mathematical concepts and then practising those skills many times, nor is it the case of a student blindly blundering on in the hope that at some point in the future they may build a relevant mathematical concept or understanding. Rather, it is a "community of learner's model" (Wilhelm, Baker and Dube, p. 7) where an authentic problem is posed and together, the student and expert other, usually a teacher, but not necessarily so, co-construct a solution for that problem. The teacher intercedes as necessary to ensure the student develops and or adopts the appropriate language to discuss the understandings. This ensures that the necessary mathematical concepts and procedures are being developed, consolidated or refined as is necessary and allows the student to make progress. The problem needs to be of sufficient complexity to ensure there is challenge in it for the student. However, the complexity should be such that with support the student is able to successfully complete the task (Wilhelm, Baker and Dube, p. 4).

As the teacher works with the student on tasks, the level of support given will vary depending on the ability of the student and the level of interaction provided in the past. As the student and the teacher work together, the student's cognitive level will increase and so the level of support may decrease during successive iterations of the development process (Wilhelm, Baker and Dube, p. 4). One Sociocultural approach to teaching and learning that may assist teachers and students to engage with mathematical modelling is Collective Argumentation (Brown \& Renshaw, 2000). 


\section{Collective Argumentation}

Collective Argumentation involves the teacher and students in ways of coming to know, do and value mathematics which reflect the investigative processes and ways of interacting employed by the mathematical community. In simple terms, collective argumentation involves the teacher and students in small group work ( 2 to 5 students per group) where students are required, initially, to individually "represent" a problem by using pictures, diagrams, drawings, graphs, algorithms, numbers, etc. Students are then required to "compare" their representations with those of other group members. This phase of individual representation and comparison provides the potential for differences in understanding of curriculum content to be exposed and examined. Subsequent talk by the students regarding the appraisal and systematisation of representations is guided by the keywords - "explain", "justify", "agree". Finally, moving from the small group to the classroom collective, the thinking within each group is validated for its consistency and appropriateness as it is presented to the whole class for discussion and validation.

\section{The teacher's role in collective argumentation}

The teacher has an active role throughout each phase of Collective Argumentation. The tasks of the teacher include: (a) allocating management of the problem-solving process to the group; (b) facilitating peer co-operation by reminding students of the norms of participation; (c) participating in the development of conjectures and refutations; (d) modelling particular ways of constructing arguments; (e) facilitating class participation in the discussion of the strengths and weaknesses of a group's co-constructed argument, (f) introducing and modelling appropriate mathematical language, and (g) providing strategies for dealing with the interpersonal issues that may arise when working with others.

The remainder of this chapter explores the effects of Collective Argumentation in making visible students' understandings as they go about knowing and doing mathematics in a novel context - an inter-school mathematics modelling challenge. Specifically, we seek to explore whether a group of students from a Collective Argumentation classroom see mathematics as providing a forum where personal understanding is privileged, that is, as providing a space where personal understandings can be expressed, re-considered, shared and co-authored. 


\section{The A.B. Paterson College Gold Coast Mathematical Modelling Challenge}

The A.B. Paterson College Gold Coast Mathematical Modelling Challenge (The Modelling Challenge) was first conceptualised and implemented in 2004. It is a joint venture between A.B. Paterson College and the Education Faculty of the Gold Coast Campus of Griffith University, supported by numerous academics from various universities, classroom teachers who have a passion for mathematical modelling and sponsored by major corporations.

The Modelling Challenge's initial brief was to cater for students in Years 4 to 11 (that is, 9 to 16 year old students) from schools across South-East Queensland. Invitations were sent to students in these schools with 80 taking up the opportunity to participate in the first year. Over subsequent years, attendance at the Modelling Challenge has continued to grow with 320 students attending in 2009.

In 2009, the Modelling Challenge attracted its first contingent of international students from Singapore. To enhance their experience at the Modelling Challenge, these international students integrated with students from an Independent College on the Gold Coast in a Mathematics Modelling Forum which allowed them to explore more of the competencies associated with Mathematical Modelling.

The drive behind the Modelling Challenge has always been to provide students with an alternative experience to challenge their thoughts about mathematics instruction and its use beyond the classroom. Many students see mathematics as being only relevant as they work though textbook problems where the answers are known by the teacher and are readily found in the back of the textbook. The Modelling Challenge aims to provide a significant contrast to this view of mathematics. There are four goals of the Modelling Challenge.

Goal 1: To encourage students to operate as Mathematicians: According to the American Mathematical Society's web site, "Mathematicians make it possible to send secure emails and buy things online. Mathematicians are essential to analyze data and design accurate models in fields as diverse as biology and finance. Mathematicians enabled researchers to complete The Human Genome Project quickly. And because of the prevalence of the computer at work and at play, mathematicians will continue to touch everyone in modern society." Hence in the 
Modelling Challenge this goal is about encouraging students to collect data, make propositions, synthesise strategies, and then implement those strategies and assess the validity of the models they produce and the conclusions they derive. To assist the realisation of this goal, there is a continuum of task design from the junior year levels through to the senior year levels allowing for different levels of instruction and scaffolding. In the younger years, students are provided with a problem and scaffolding so that they are able to make progress towards a solution. The context is carefully orchestrated so that students have significant opportunity to develop their own conjectures, test those conjectures and then to refine them. In Years 10 and 11, students identify a context and pose a problem of interest to them based on that context, collect data, and develop mathematical models and use those models to make predictions, all the while, identifying the assumptions necessary for their models to be valid and determining the limitations associated with their model and the process. Across all the year levels students learn about the modelling cycle while they engage with the context and are provided feedback by a mentor. The students are encouraged to engage in multiple iterations of the modelling cycle.

Goal 2: To provide opportunities for students to engage in tasks that are novel and interesting, where the answer is not readily accessible by either the teacher or the student and where the responses are dependent on the assumptions the students make. In the junior classes students are generally involved in building something concrete from which they are able to collect data. In past modelling challenges, students have considered problem contexts such as 'What shaped rotor gives the greatest energy output for a wind generator'. Students were given the generator, and materials to make a rotor for a wind generator. They then needed to determine the area the rotor and measure the energy generated by that particular configuration using a voltage probe. Students subsequently reduced the area of the rotor and considered the effect this had on the amount of energy produced. When the rotor had less area, it could spin faster thus generating more electricity, however, if the area became too small, it would not receive sufficient thrust from the wind and so electricity generation would reduce. Students were required to determine (for their rotor design) which configuration had the optimum electricity generation.

Goal 3: To work with students from different schools. When mathematicians work together to solve a problem they bring their individual strengths and experiences to the table to illuminate the problem and postulate different strategies. In many 
instances, it may be that they only work together on this project and then disperse; we want students to experience this. To facilitate this goal, students are placed into groups of four within the year levels: years 4 and 5, years 6 and 7, years 8 and 9, and years 10 and 11. Ideally, the groups are constructed so students from different schools are spread across the groups with care taken to ensure there is a balance across the year levels and the sex of the students. Groups in the upper age levels tend to be more fluid and while they are initially placed into groups, group structure tends to be more fluid. Hence in the Modelling Challenge it is the intention of this goal to encourage students to work collaboratively to model a real life situation.

Goal 4: To provide students with sufficient time to be able to try different ideas and ascertain "Which solution is the better?" In many classroom situations, students get the idea that there is only one single answer and one single procedure used to get that answer and that the teacher has all the answers. They may also ascribe to the belief that to be good at mathematics, they must use a specific procedure to arrive at a specific answer. The Modelling Challenge attempts to facilitate in student's thinking, a different view of mathematics; one where time is needed, where they are able to engage with the task, to identify the mathematics they know that they feel will be useful, to create ideas, and to reflect on the conclusions they have made. Hence the Modelling Challenge is conducted over two days. The first day allows students to engage with the task and to try different strategies. During the second day the students, then armed with the results of the previous day, are encouraged to reflect upon and to refine their strategies and the resulting predictions. Each group prepares a poster of their findings and makes an oral presentation of their work to their peers and the class mentor. During this presentation, students are able to question and to challenge the conclusion provide by the presenting group. This provides more feedback to the students in terms of their conclusions and can challenge them to think more deeply about their conclusions and the mathematics used to develop those conclusions.

\section{A Case Study}

\section{Participants}

This case study will follow the conversations of a group of students as they engage in a particular modelling task. This group of students participated in the Year 
6/7 section of the inter-school mathematics modelling challenge. Three of these students ( 2 girls \& 1 boy) - Helen, Nicole, and Neil - form the focus of this study.

The Task

Each group was required to design a mini-golf hole - complete with blockers, tunnels and other obstacles - and create a theoretical hole-in-one path of the ball such that each angle of incidence equalled the corresponding angle of reflection. Over the two days of the modelling challenge, the students were engaged with the task of designing, building to scale, and mathematically modelling a mini-golf hole. Initially each group was required to represent their mini-golf hole design on graph paper, provide a spreadsheet showing the segment angles, and linear equations, and provide a short journal entry of their experience with the challenge. Each group received a poster board, a piece of green felt, wooden blocks, cardboard tubes and a marble along with graph paper and a criteria checklist. Four computers, connected to the internet were available for the students to use. Clarification of task requirements was provided to each group by a mathematics educator, however no direct teaching of task content was provided.

Data Analysis

Bakhtin's (1986) notion of 'voice' was used to analyse the transcripts. Bakhtin (1986) formulated a theory of voice that emphasized the active, situated, and functional nature of speech as it is employed by various communities within a particular society. Taking the notion of 'utterance' rather than 'word meaning' as a basic unit of communication, Bakhtin maintained that in dialogue with others, people align themselves within different speaking positions or voice types as they produce or respond to an utterance or a chain of utterances. Such voice types reflect the social ways of communicating that characterize various group behaviors (for example, professional communities, age groups, and socio-political authorities) that a person has had the opportunity and/or willingness to access. As such, 'voice' as used here, encompasses "what" is being said, the "way" in which it is spoken, and the positioning of speakers in relation to the authority framework established within the communication.

\section{Analysis and Discussion}

We enter the mathematics modelling challenge when Helen, Nicole, Neil and Aaron (a student from a different school to the others) are preparing a short journal 
entry of their experience with the challenge. The extract is taken from the second targeted data collection session held in the morning of the second day of the challenge (see Table 1).

Table 1

Maybe our whole group learnt about it

\begin{tabular}{lll}
\hline Turn & Speaker & Text \\
\hline 01 & Nicole & Aaron learnt... What did you learn? \\
02 & Aaron & I learnt lots. \\
03 & Nicole & Well then tell us. \\
04 & Aaron & I learnt about slope. \\
05 & Neil & Maybe our whole group learnt about it. \\
06 & Helen & I didn't (learn about slope), I had to do it $(\mathrm{y}=\mathrm{mx}+3)$. \\
07 & Neil & (I learnt) About the equations. \\
08 & Helen & Y $=\mathrm{mx}+3$ \\
\hline
\end{tabular}

We enter the script where Nicole is recognising Aaron's 'belonging' in the group by asking him what he had learnt from engaging with the mini-golf task. Instead of accepting Aaron's general response (turn 2 - I learnt lots) and then moving to record the responses of the other members of the group who were from her school, Nicole encourages Aaron to be reflective and to consider the specifics of what he had learnt (turn 3 - Well then tell us). This action reflects a reason for using the practices of Collective Argumentation in the modelling challenge, "We want to encourage our students to be reflective and consider how the various concepts (in mathematics) are related".

Collective Argumentation privileges this level of understanding by requiring students to explain and justify their learning on a regular basis, therefore, making knowledge public. Explaining and justifying involves the gathering and sharing of evidence that satisfies disciplinary constraints associated with coherence and logic. Explaining and justifying allows students to become conscious of others' ideas and points of view, allowing processes of thought as well as products to become visible.

This privileging of reflecting on understanding continues as the other members of the group comment on their personal understandings relating to 'slope'. Here we see students being reflective, considering what they have learnt (turn 7-About the equations) and what they did not learn (turn 6-I didn't, I had to do it). However a student saying they have learnt it does not mean they understand it, as Helen reveals in the next sequence of text (see Table 2). 
Table 2

I knew something that you didn't know

\begin{tabular}{lll}
\hline Turn & Speaker & Text \\
\hline 09 & Nicole & Helen, what did you learn today? \\
10 & Helen & Y $=\mathrm{mx}+3$ \\
11 & Nicole & Didn't you already know that? \\
12 & Helen & No, how to do it, like I knew what it (slope) was, I just didn't \\
& Now how to do it (slope). \\
13 & Helen & Didn't you know how to do it (slope)? \\
14 & Nicole & You (Nicole) didn't. \\
15 & & Yes I did, well I knew how to do it the obvious way, I knew \\
& & how to do it on a graph, but on quadrant things (quadrants of a \\
16 & Neil & full grid). \\
\hline
\end{tabular}

Here we see Helen and Nicole linking what they know, considering a different strategy (using $\mathrm{y}=\mathrm{mx}+3$ [turn 10] or graphing a line on a grid [turn 15]) and recognising they are doing the same thing. Through this text, we see Helen and Nicole selecting and transferring the mathematical tools they had leant in the classroom to this context and recognising that there are different ways of applying those tools and different levels of knowing about and using mathematical tools.

This form of teaching and learning privileges the recognition of multiple representations of a mathematical idea through requiring students to individually represent a solution or idea about a task and to compare their representation with others. When students complete a brief written response to a text, or a solution to a problem, or an evaluation of the effectiveness of an experiment, they are more likely to participate in any discussion that follows, ask questions of others, share ideas with others, and to self-monitor their understanding (Gaskins, Satlow, Hyson, Ostertag, \& Six, 1994). Comparing representations allows students to see what is the same and what is different about their ideas and interpretations. In the process, it can help students learn by making them view concepts from different perspectives, and can be affirming as students see congruence between ideas and representations (Feltovich, Spiro, Coulson, \& Feltovich, 1996).

Through recognising that Nicole is using a graphical approach to completing the task and that Helen is using an algebraic approach, the students pave the way for relating procedural to conceptual understanding, as illustrated in the following sequence (see Table 3). 
Table 3

We used it, but we didn't know how

\begin{tabular}{|c|c|c|}
\hline Turn & Speaker & Text \\
\hline 17 & Nicole & Neil, what did you learn? \\
\hline 18 & Neil & I learnt that, I learnt just that $(y=m x+3)$. \\
\hline 19 & Nicole & What do you mean just that? $\mathrm{Y}=\mathrm{mx}+3$ ? \\
\hline 20 & Neil & $\begin{array}{l}\text { Just write everybody learnt that }(y=m x+3) \text {, because we all } \\
\text { did learn that, yeah everybody learnt it. }\end{array}$ \\
\hline 21 & Nicole & I need an eraser. \\
\hline 22 & Neil & $\begin{array}{l}\text { So you don't have to write just Aaron (learnt } \mathrm{y}=\mathrm{mx}+3 \text { ) } \\
\text { cause we all learnt it. }\end{array}$ \\
\hline 23 & Nicole & $\begin{array}{l}\text { Did anyone else learn anything that's not there (in the journal } \\
\text { entry)? }\end{array}$ \\
\hline 24 & Neil & Um maybe we ... \\
\hline 25 & Nicole & How to use slope or anything? \\
\hline 26 & Helen & That (slope) is part of the equation. \\
\hline 27 & Neil & $\begin{array}{l}\text { Yeah, that's part of the equation. Let's see, what about how to } \\
\text {.. }\end{array}$ \\
\hline 28 & Aaron & $\begin{array}{l}\text { Did you know that equation }(\mathrm{y}=\mathrm{mx}+3) \text { before we came (to } \\
\text { the challenge)? }\end{array}$ \\
\hline 29 & Nicole & We used it $(y=m x+3)$, but we didn't know how. \\
\hline 30 & Helen & That's how to find out 'm'. \\
\hline
\end{tabular}

Once again (turns $17 \& 19$ ) a member of the group, Neil, is asked by Nicole to explicate what he learnt from engaging in the mini-golf task. Neil's admission that he learnt about slope (turn 22 - So you don't have to write just Aaron cause we all learnt it) marks a moment in the conversation when this grouping of students from two different schools, have become a group who are willing to take ownership of their learning. In so doing, links are made between 'how to use slope' (turn 25) and the algebraic equation $-\mathrm{y}=\mathrm{mx}+3$ (turn 26 - that's part of the equation) and between the concept of 'slope' and its algebraic representation 'm' (turn 30).

Collective Argumentation privileges linking conceptual with procedural understanding and linking individual with collective understanding by requiring that the group attain consensus about a response to a task that they can present to the whole class - a response that each member of the group understands. Consensus based on understanding is the end product of a process of considering and critiquing. Students negotiating a common understanding of a representation or idea take learning from the co-operative to the collaborative plane of learning.

This willingness to collaborate in the sharing of understandings continues in the next sequence of text which was recorded in a moment of interest when the group extended its boundaries to include members from other groups undertaking the 
challenge. We enter the script where Helen has just explained to her group how to find the slope ' $\mathrm{m}$ ' in the equation $\mathrm{y}=\mathrm{mx}+3$ (see Table 4). During the explanation, students from other groups gather around to listen. The students included Gail (another student from Nicole, Helen and Neil's school).

Table 4

Let me explain how to do ' $m$ '

\begin{tabular}{|c|c|c|}
\hline Turn & Speaker & Text \\
\hline 31 & Nicole & Yeah, I got that, I got it $(y=m x+3)$. \\
\hline 32 & Neil & Yeah I do (understand). \\
\hline 33 & Nicole & $\begin{array}{l}\text { Because I didn't really get it }(y=m x+3) \text { before, } \\
\text { but I understand now. }\end{array}$ \\
\hline 34 & Gail & So you (Helen) just explained how to do 'm'? \\
\hline 35 & Neil & Let me explain how to do 'm'. \\
\hline 36 & Gail & $\begin{array}{l}\text { He (points to a boy in her group) needs to figure } \\
\text { out also how to do 'b' (the Y Intercept). }\end{array}$ \\
\hline 37 & Helen & $\mathrm{mx}+3$, equals 'b' equals $\mathrm{Y}$ intercept. \\
\hline 38 & Gail & $\begin{array}{l}\text { He (a boy in her group) doesn't get (understand) } \\
\text { it. }\end{array}$ \\
\hline 40 & Helen & Whatever $Y$ intercept is, is ' $b$ '. \\
\hline 41 & Gail & He (a boy in her group) doesn't understand. \\
\hline 42 & Helen & $\begin{array}{l}\mathrm{Y} \text { intercept is when the } \mathrm{Y} \text {, where the point } \mathrm{Y} \text { is. } \\
\text { Well then you (Neil) can explain it then. }\end{array}$ \\
\hline
\end{tabular}

The interaction of students in the above text is interesting for students engaged in an inter-school mathematics challenge. The challenge relating to the mini-golf course can be won by one group only. Helen, in demonstrating her understanding of how to find the slope of a line between two points provides an explanation that is attended to by students not in her group. Not only does Helen share her understanding with Nicole (turn 31) and Neil (turn 32), but receives a request from Gail (a member of another group) to explain again how to find the slope, as a boy in Gail's group does not understand. Neil requests permission to provide the explanation (turn 14). However, Helen simply revoices the main point of her explanation (turn 16). Upon receiving a signal from Gail that this revoicing is insufficient (turn 19), Helen gives Neil permission to explain. Neil goes on to present an explanation to the gathered audience that results in a number of students from different groups working together to build a model that they can use to make predictions.

Collective Argumentation privileges a view of mathematics as being about engagement in communal practice by requiring each group to present their agreed approach to the class for discussion and validation. Such presentations of group work permit students to engage with the conceptual content of a lesson at their level, to 
employ their own prior experiences, preconceptions and language, and to distribute the nature of their knowing across a group rather than in a fashion that focuses on any one individual.

\section{Conclusion}

This chapter set out to describe how mathematical modelling can provide for students a view of mathematics where the mathematics they use has relevance outside the classroom. While building a mathematical model students must do much more than practise a set of procedures. They need to interpret the context, they need to identify suitable assumptions, using the mathematics they need to look for consistency in the mathematics and consensus between the mathematics and the context. If they do not find consistency and consensus, they then need to revisit the context and consider why their model is not a suitable representation. Once the students have the model they are then interested as to whether the model is able to be used to make predictions.

As teachers involved in the mathematical modelling we need to know what the students are thinking. Further, as well as developing an understanding of the mathematics we need to ensure students are able to operate together to build on each other's understandings reaching a level of sophistication very few students would naturally achieve on their own.

The nature of the learning displayed by Helen, Nicole, and Neil as they engaged with the mathematics challenge in designing a hole-in-one mini-golf course, suggests that these students view doing the mathematics as providing a forum where personal understandings can be expressed, re-considered, shared and co-authored - an unusual stance for students engaged in what might be viewed as a mathematics competition. The above analysis of student-student interaction suggests that within this group's way of doing the mathematics challenge, understanding emerged around shared practice. That is, a collaborative space emerged where a voice of inquiry was enacted that privileged: (a) the relating of conceptual understanding to procedural understanding (e.g., determining slope and the $\mathrm{Y}$ intercept to build the equation, $\mathrm{y}=$ $\mathrm{mx}+\mathrm{b}$ ), (b) group ownership of learning over individual performance (e.g., designating new learning about slope to the whole group rather than just to an individual within the group), (c) mathematising, that is, not only knowing the 
mathematics, but also how and when to use the mathematics (e.g., as suggested by Nicole's statement - We used it $(y=m x+3)$ but we didn't know how $)$.

Within this collaborative space, on-going processes for adding meaning to the mini-golf task such as representing, comparing and explaining were used by the students in a fashion that allowed their individual representations, ideas and points of view to become products of the moment, able to be used by others to progress understanding. Students' interactions, as portrayed in the above conversations, imply that within the collaborative space constructed by the students within the constraints of the mathematics modelling challenge, students not only co-constructed knowledge, but developed also an awareness of the 'self' as operating with tools of mathematics (e.g., $y=m x+b)$, of the self operating as a mathematician.

The interactions between Helen, Nicole, and Neil occurred within a real novel context centred on real mathematics challenges. Rather than displaying individual personalities engaged in competitive intellectual practice, Helen, Nicole and Neil were drawn into a culture of inquiry that displayed distinct co-operative and collaborative relationships. This culture is further testified through student feedback forms about the modelling challenge collected over the past five years that have attested to students enjoyment to a group based modelling process. In response to the question, "What did you find most enjoyable about the mathematical modelling challenge?", students consistently referred to working with their peers and engaging with challenging mathematical tasks.

This chapter has provided a sense that teachers can change students' views of the learning mathematics through engaging students in mathematical modelling. Such engagement can not only lead to students talking about and doing mathematics outside the classroom, but also provide teachers with the means to change their sense of self-efficacy in the classroom. Supported by practices such as those associated with Collective Argumentation, teachers may utilise tasks that not only permit students to generalise and objectify their thinking, to employ practices that promote consistency in their reasoning and consensus in their ways thinking, but also create contexts where students can safely discuss their ideas, accept guidance from others, and reflect upon their own practice.

\section{References}


American Mathematical Society: http://www.ams.org/profession/career-info/math-work/math-work, 30.11.11.

Bakhtin, M. M. (1986). Speech Genres and Other Late Essays. (C. Emerson \& M. Holquist, Eds., V. W. McGee, Trans.). Austin: University of Texas Press.

Boaler, J., \& Greeno, J. G. (2000). Identity, agency and knowing in mathematics worlds. In J. Boaler (Ed.), Multiple perspectives on mathematics teaching and learning (pp. 171-200). Westport, CT: Ablex.

Brown, R.A.J., \& Renshaw, P.D. (2000). Collective argumentation: A sociocultural approach to reframing classroom teaching and learning. In H. Cowie and G. van der Aalsvoort (Eds.), Social Interaction in Learning and Instruction: The Meaning of Discourse for the Construction of Knowledge (pp. 52-66). Amsterdam: Pergamon Press.

Feltovich, P.J., Spiro, R.J., Coulson, R.L., \& Feltovich, J. (1996). Collaboration within and among minds: Mastering complexity, individually and in groups. In T. Koschmann (Ed.), CSCL: Theory and practice of an emerging paradigm (pp. 25-44). Mahwah, N.J.: Lawrence Erlbaum Associates.

Galbraith P.L., Stillman G., Brown J., Turning Ideas into Modelling Problems, In Lesh R., Galbraith P.L., Haines C.R., Hurford A., (Ed.), Modelling Students' Mathematical Modelling Competencies, ICTMA13, 133-144, Springer.

Galbraith, P. (1989). From applications to modelling. In D. Blane \& M. Evans (Eds.), Mathematical modelling for the senior years (pp. 78-86). Parkville: The Mathematical Association of Victoria.

Galbraith, P. (1995). Assessment in mathematics: Developments, innovations and challenges. In L. Grimison \& J. Pegg (Eds.) (1995). Teaching Secondary School Mathematics. (pp. 289-314). Sydney: Harcourt Brace.

Gaskins, I.W., Satlow, E., Hyson, D., Ostertag, J., \& Six, L. (1994). Classroom talk about text: Learning in science class. Journal of Reading, 37(7), 558-565.

Ginsburg, H. P., \& Seo K-H. (1999). Mathematics in children's thinking. Mathematical Thinking and Learning, 1(2), 113-129.

Lingefjard, T. (2006). Faces of Mathematical Modelling. Zentralblatt Fur Didaktik der Mathematik, $38(2), 96-112$.

National Council of Teachers of Mathematics (NCTM). (2000). Principles and standards for school mathematics. Reston, VA: Author. Retrieved from http://www.standards.nctm.org.

Pajares, F., \& Graham, L. (1999). Self-Efficacy, Motivation Constructs, and Mathematics: Performance of Entering Middle School Students. Contemporary Educational Psychology, 24, 124-139.

Perkins, D.N. (1992). Smart Schools: Better Thinking and learning for Every Child. New York: The Free Press.

Smith J.P. III (1996), Efficacy and teaching mathematics by telling: A challenge for reform. Journal for Research in Mathematics Education, 27(4), pp. 387-402.

Swetz, F., \& Hartzler, J., S. (1991). Mathematical modelling in the secondary school curriculum. The National Council of Teachers of Mathematics: Reston, Virginia.

Van Oers, B. (1998). From context to contextualizing. Learning and Instruction. Vol. 8, No. 6, pp. 473488.

Vygotsky, L (1987) Thinking and Speech. In R.W. Rieber \& A S Carton (Eds.), The collected works of L.S. Vygotsky, Volume1: Problems of general psychology. New York: Plenum Press.

Wertsch, J. V. (2002).Voices of collective remembering. New York: Cambridge University Press.

Wilhelm, J., Baker, T., \& Dude, J. (2001). Scaffolding adapted from strategic reading: Guiding students to lifelong literacy. New Hampshire USA.: Heinemann, a division of Reed Elsevier Inc., $<$ http://www.myread.org/scaffolding.htm $>$ 